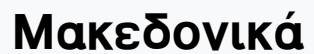

Tóp. 4, Ap. 1 (1960)

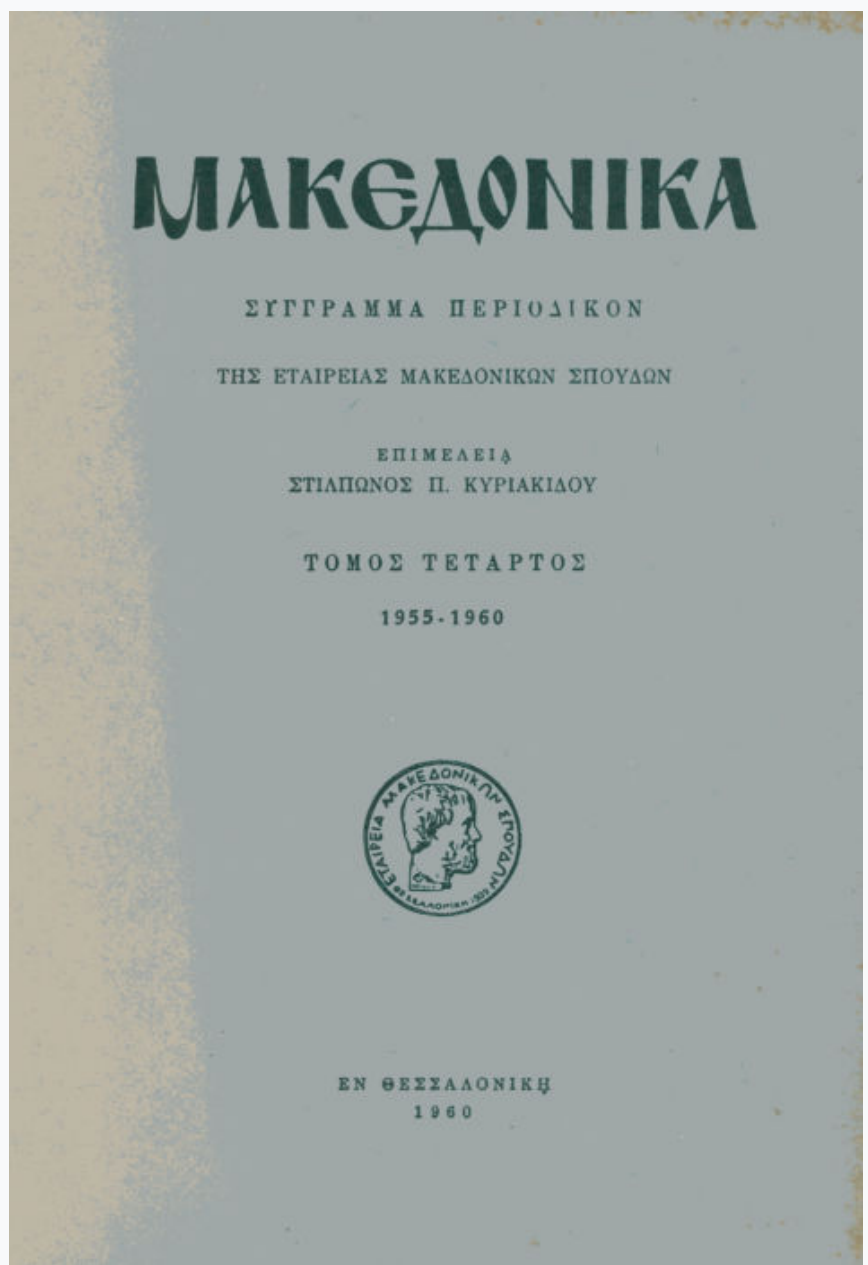

\section{Tyrcki docymenti za Makedonckata istorijia} 1827-1839

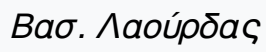

doi: 10.12681/makedonika.757

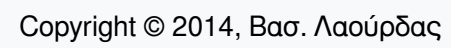

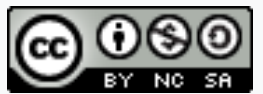

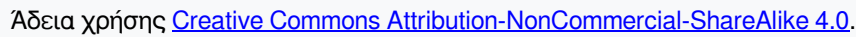

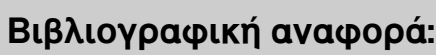

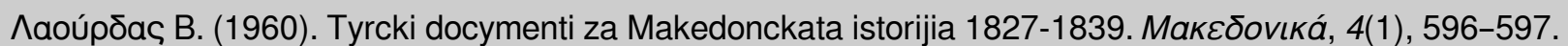
https://doi.org/10.12681/makedonika.757 


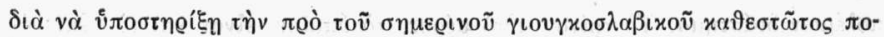

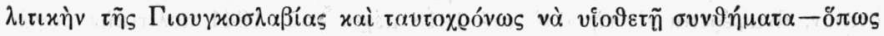

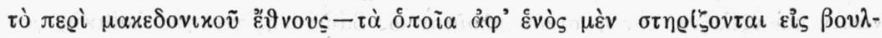

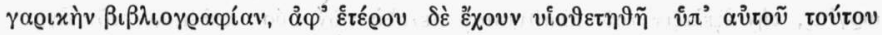

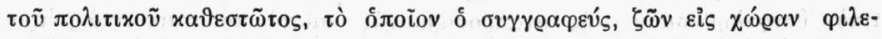

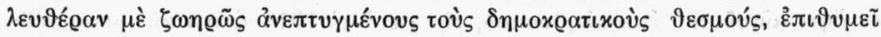

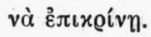

BAE. NAOYPAAE

Tyrcki docymenti za Makedonckata istor i j a 1827-1839, V, Institut za Nazionalna istorija, Ckopje 1958, $\sigma \varepsilon \lambda .219$.

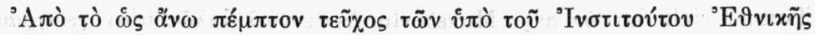

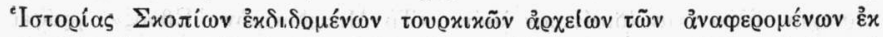

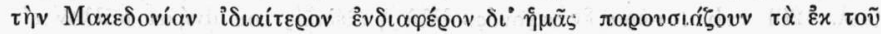

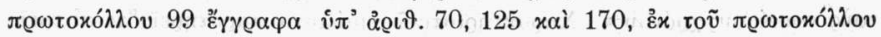

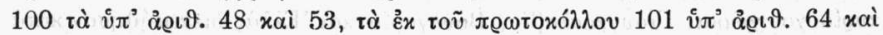

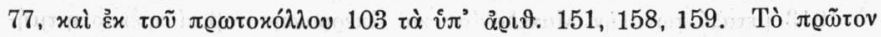

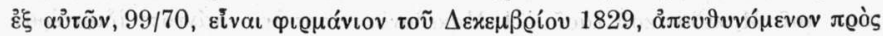

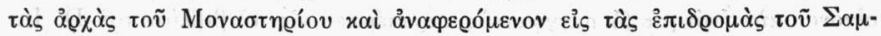

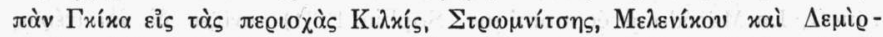

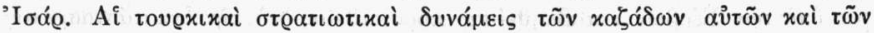

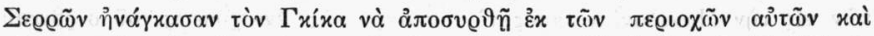

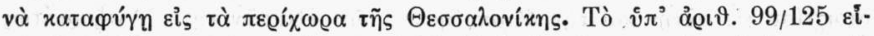

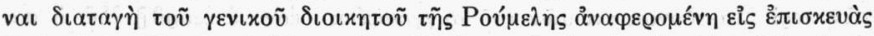

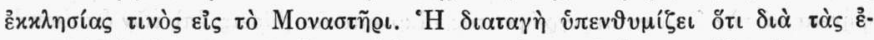

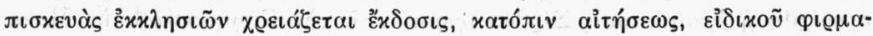

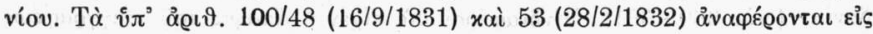

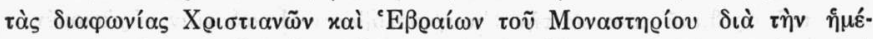

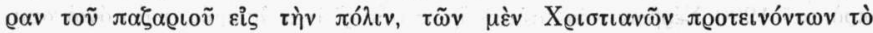

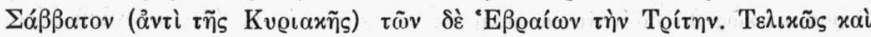

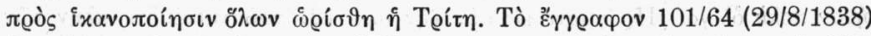

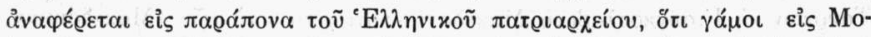

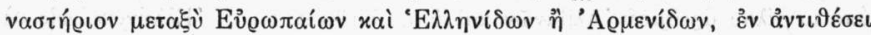

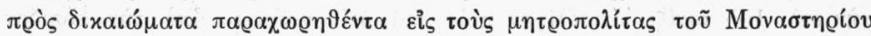

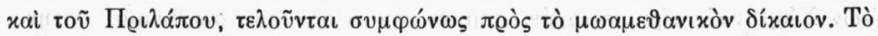

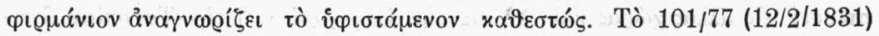

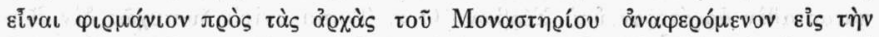

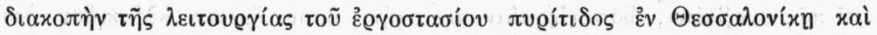

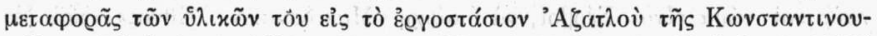

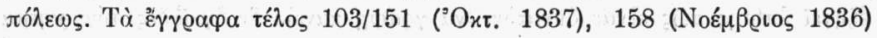




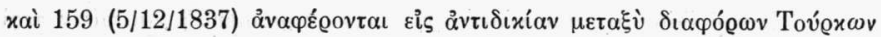

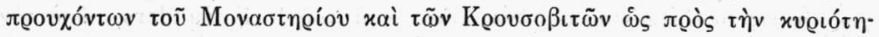

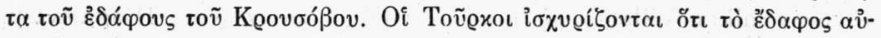

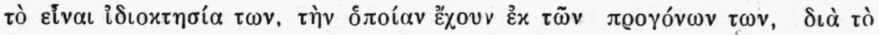

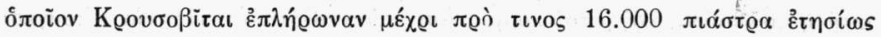

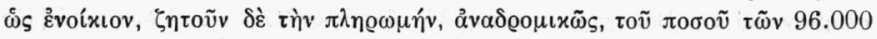

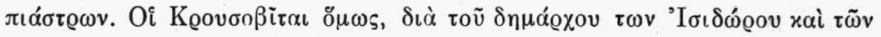

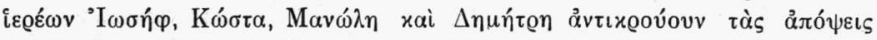

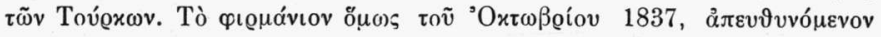

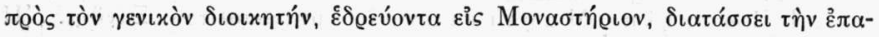

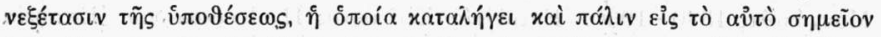

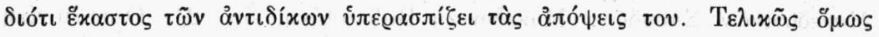

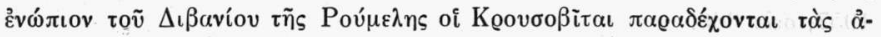

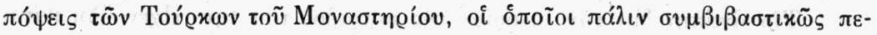

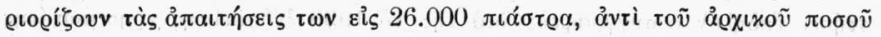
$\tau \tilde{\omega} v$. 96.000 .

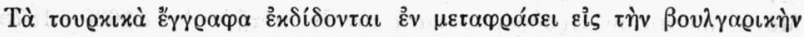

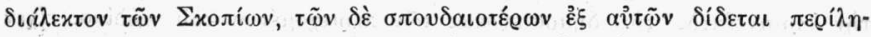

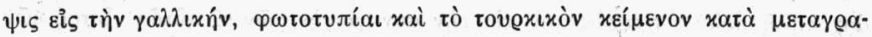

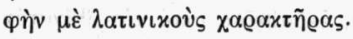

BAE. NAOYPAAE

J oe 1 Martin $\mathrm{H}$ a 1 pern, A Serbian village. Colum-

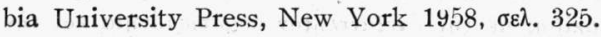

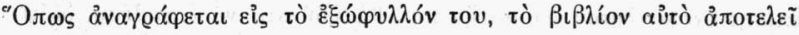

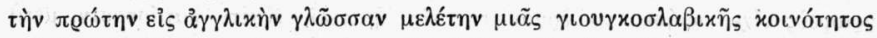

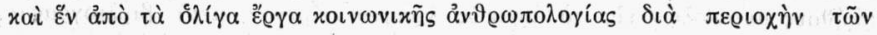

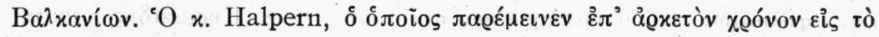

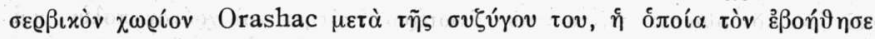

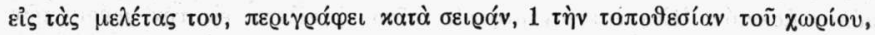

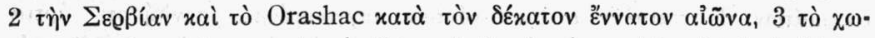

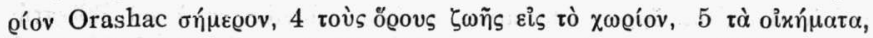

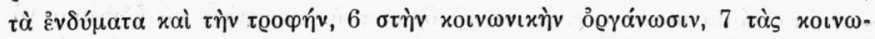

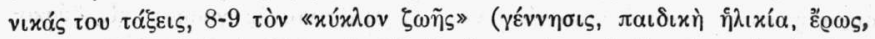

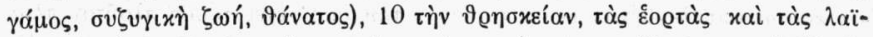

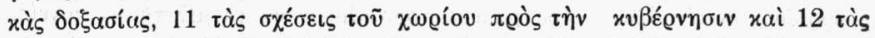

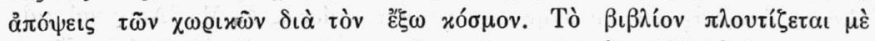

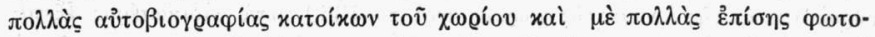

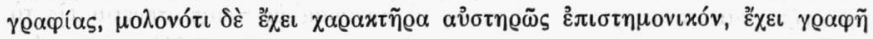

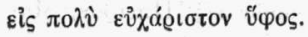

